\title{
Community Engagement in Forest Care: What it Means to the People in the Forest ${ }^{1}$
}

\author{
Muhammad Adha Shaleh*
}

In today's forest management system, the state and its departments constitute the majority stakeholders in forest care. They have ignored the conservation role of forest communities in the forest. This practice has already bred narratives about our environment: declining biodiversity, the commodification of nature, land conflicts, overlapping forest ownership, and indigenous claims to land rights in the forest. This scenario deserves attention. What is crucial and necessary is to present an alternative view to mainstream thinking on the forest management system (state control). It is for this reason that there has been a surge call to reform forest planning by engaging indigenous people in the ongoing narratives of forest discussions.

To explore the current rhetoric of forest management, this writer identified South East Pahang Peat Swamp Forest (SEPPSF) as a case study. This forested area covers approximately 200,000 ha of land, accounting for $60 \%$ of the total forest coverage of the Malay Peninsula. Signified by its ecological richness, the SEPPSF attracts enormous activity, including logging, the extraction of NonTimber Forest Products (NTFP), commercial plantation, research activities, and tourism. Most SEPPSF land areas have been classified as agricultural development, whereas $5.6 \%$ of the forest reserves have been logged. Due to its ecological significance, there is a need for holistic strategies to protect its precious ecosystem. So, in implementing forest conservation policy, the state holds usufruct rights to manage the forest - marking out lands for forest conservation and resettling local communities. The state has not precluded the indigenous people from using the forest and collecting food from it, but as the result of conservation boundaries, the Orang Asli communities have become detached from nature. This dominant state-based forest system provokes an alternative view: the advocates of indigenous-based forest management, popularly known as community forestry, suggest that people who live closer to the land are the ones who should be taking care of the forest. Community forestry, the argument goes, gives a greater right for community engagement in forest care. In addition, it suggests that people who are closer to nature will continue to feel the sense of belonging to it. Thus, they are the prime candidates to maintain the forest and its ecosystem. 
In general, according to my field study's record, the idea of community forestry has been supported by Orang Asli communities. To achieve this vision, however, the authorities must collaborate with local communities. Such collaboration in forest care offers these benefits: biodiversity protection, income opportunities for the locals, environmental education and tourism. In advancing this collaboration, the authorities and their subsidiaries establish a friendship with the Orang Asli by recognising the latter's ideas for conservation planning. This style of collaboration forms a pre-requisite for a successful community engagement in forest care.

In addition, the idea of community engagement must be embedded in forest conservation activities that bring forest people closer to the forest by utilising their knowledge, constituting the acceptance and recognition of their heritage land, history, livelihoods, traditions, norms and the rules that dictate their behaviours toward the environment. Also, their ecological wisdom that contains conservation ethics. In other words, resuscitate the forest people's environmental knowledge in current forest planning. This knowledge is unique because it is acquired by local people through experience, experimentation, observation and an understanding of the environment. They have used it historically for health care, agricultural practices, food preparation and so forth. Often communicated through oral traditions by family members across generations, local knowledge continues to guide the Orang Asli and is reproduced according to the following ecological conditions: rains, floods, the growth of fruits, track and traces of animals and so on. In the Orang Asli's words, "It is impossible to carry out forest conservation, cultivation of traditional herbs without our environmental knowledge. We know leaves that can be eaten and leaves that cannot be eaten. We know what is inside the wood and what is inside the water." In short, local knowledge is useful for conserving the complex biological diversities in the forest, for increasing forest covers and for preventing the living landscape from degradation.

As the community-government collaboration comes into form, a genuine engagement between the authorities and the forest people comes into the picture. This will usher in significant changes in community forestry. The following statement underlines the importance of genuine community engagement with forest communities. "Engaging the Orang Asli communities in forest conservation project means they are able to speak up and tell their narratives about forest conservation. When Orang Asli people are able to tell local versions of environmental practices to outsiders who may not be very well informed on local conservation practices, we can utilize their forest conservation ethics, in which their ancestors have bestowed upon them from generations. This is why local knowledge is crucial to community-based forest conservation." Therefore, any effort to genuinely engage the Orang Asli in forest conservation will lead to an alternative forest system, one that goes beyond the state-based forest paradigm. 
In conclusion, discussions about community engagement transcend mutual relationships between the authorities and local communities by also covering major aspects of good will, sincerity and integrity. In advancing the new narrative about forest care perpetuated in community forestry, there is a need for the authorities to institutionalise it, together with a recognition of community rights in forest care, at the local level. To advance this idea, the higher authorities have to relegate forest management roles in local communities. To execute this plan, it needs to originate from community engagement, to be used as a tool to revive local knowledge for a holistic conservation plan. From the perspectives of the Orang Asli people, community engagement is by far the closest recognition, by the state, of their existence in the forest. From the lens of advocates, it is a bottomup approach to collaborative forest management. It tells us the importance of keeping the forest sustainable by integrating traditional indigenous knowledge with scientific knowledge. Finally, the significance of community engagement in forest care can be summarised in the following order:

- Government recognition of local communities as stakeholders in forest conservation activities;

- A full incorporation of local communities' knowledge, aspiration, ideas and needs in the forest;

- Fostering government and local communities' partnership based on goodwill and an understanding of what is essential to local communities with regard to their forest landscape.

\section{Notes}

* Muhammad Adha Shaleh is Research Fellow at IAIS Malaysia. He may be reached at adha@iais.org.my.

1. The writer did a field interview with the Orang Asli Jakun in South East Pahang Peat Swamp Forest (SEPPSF), Malaysia. 